\title{
Design Of Launch Systems Using Continuous Improvement Process
}

\author{
R. W. Brown \\ NASA MSFC, Huntsville, AL, USA
}

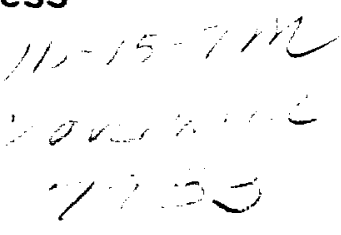

\begin{abstract}
The purpose of this paper is to identify a systematic process for improving ground operations for future launch systems. This approach is based on the Total Quality Management (TQM) continous improvement process. While the continuous improvement process is normally identified with making incremental changes to an existing systems, it can be used on new systems if they use past experience as a knowledge base. In the case of the Reusable Launch Vehicle (RLV), the Space Shuttle operations provide many lessons.

The TQM methodology used for this paper will be borrowed from the United State Air Force "Quality Air Force" Program. There is a general overview of the continuous improvement process, with concentration on the formulation phase. During this phase critical analyses are conducted to determine the strategy and goals for the remaining development process. These analyses include analyzing the mission from the customer point of view, developing an operations concept for the future, assessing current capabilities, and determining the gap to be closed between current capabilities and future needs and requirements. A brief analyses of the RLV, relative to the Space Shuttle, will be used to illustrate the concept.

Using the continuous improvement design concept has many advantages. These include a customer oriented process which will develop a more marketable product and a better integration of operations and systems during the design phase. But, the use of TOM techniques will require changes, including more discipline in the design process and more emphasis on data gathering for operational systems. The benefits will far outweigh the additional effort.
\end{abstract}

\section{Introduction}

The top emphasis in the launch vehicle design world is the reduction of launch costs. This emphasis is illustrated by the increasing number of low cost launch systems in study, design, and early operations. Why all this sudden interest in reducing costs?
There are several major reasons. First, the government, a major user of launch services, has decided to launch its payloads (where feasible) on commercial launch vehicles. Given that most government agencies will be forced to reduce their budgets, the government will be looking for the most economical and efficient launch systems. Second, the marketing of launch services to commercial industries is also an area of increased competition. The Ariane launch system continues to be the predominant player in the launch services arena, but it and the $U$. S. launch vehicle manufacturers will face increased competition from Japan, Russia, and China. Finally, many believe that if launch costs can be reduced sufficiently then new customers for launch services will enter the market.

But is launch cost the only factor? More likely the customer for launch services, a government or private entity, is looking for the best value. To the launch services customer value maybe a function of cost, dependability, reliability, or other factors. value to the customer is the heart of Total Quality Management (TQM).

It is the purpose of this paper to look at the design of operations for new launch systems from the Quality perspective. Unfortunately this paints a rather broad perspective, so some limits must be established. First, the paper will be limited to reusable launch vehicles, and more specifically to the vehicle turnaround process. These are the actions necessary to process the vehicle from the landing on one mission to liftoff on the next. Turnaround operations were selected because they are a key value driver in reusable launch system operations. Second, the examples utilize the proposed Reusable Launch Vehicle (RLV) with Space Shuttle operations providing the knowledge base. Third, because it is impossible to evaluate the specific operations for every RLV configuration, the level of analysis will be kept at the subsystem level. In turn, the subsystems considered will include only those common 10 most RLV configurations. Fortunately most configurations have the same basic subsystems. Finally, this paper does not intend to provide solutions for improving launch system turnaround processing. Rather this is an example of how TOM should be applied to the questions of ground processing and customer value.

Copyright (C) 1995 by the American Institute of Aeronautics and Astronautics, Inc. No copyright is asserted in the United States under Title 17, U.S. Code. The U.S. Government has a royalty-tree license to exercise all rights under the copyright claimed herein for Governmental purposes. All other rights reserved by the copyright owner. 


\section{Continuous improvement}

The heart of Total Quality Management is continuous process improvement. Continuous process improvement is a systematic, iterative method of improving a process. Many organizations have instituted continuous process improvement, each using an approach best suited for their environment.

The basis for this analysis is the Quality Focus method used by the United States Air Force as part of the Quality Air Force (QAF) program. This approach was selected because it is essentially driven by aircraft operations. (Since the RLV is striving toward aircraft-like operations this appears to be a good match.) In addition, it has the advantage of being well documented.

Quality Focus is an iterative process based on the Shewhart cycle, in which there are four stages for each process review iteration. [1:7†] These are plan, do, study, and act. During the planning stage data is gathered on the existing process and it is analyzed for potential areas of improvement. Based on the results of the planning stage, potential improvements will be implemented on a small scale during the "do" stage. During the study stage the results of the pilot projects will be analyzed to see if there are significant improvements. Finally, if there are significant improvements, the improvements will be made a permanent part of the process during the "act" stage. [1:233]

The Air Force Quality Focus method tailors the Shewhan cycle to fit the activities necessary for process planning. The relationships between Quality Focus and the Shewhart Cycle are illustrated in Figure 1. As illustrated in the ligure the Quality Focus is also broken down into four phases; formulation, deployment, implementation, and review. As noted in the illustration these phases overlap the stages of the Shewhart cycle. [1:71]

The formulation phase of the cycle develops a plan for implementing continuous improvement. During this phase the organization determines the purpose of the process by clearly identifying the organization's mission, its customers, and the customer's needs, requirements, and desires. It evaluates where the organization is now and where it wants to be in the future with respect to its goals. Finally the organization determines the gap between the two, and sets goals and objectives for making the improvements. [1:71]

The second phase of the quality focus is deployment. This phase also considers the goals and objectives of the effort. This is repeated since there are often trade-offs to be made between the formulation and deployment stages. Based on the goals and objectives, functional plans are developed for implementation of changes. [1:74]

The third phase of Quality Focus is implementation. Here the functional plans developed in the previous phase are used to make corrections to the process flow. But implementation does not stop here, data must be collected for use in the final phase of the process. [1:75]

The final phase is the review of the data collected to ascertain if the changes to the process are effective. If the reviews show a positive result,

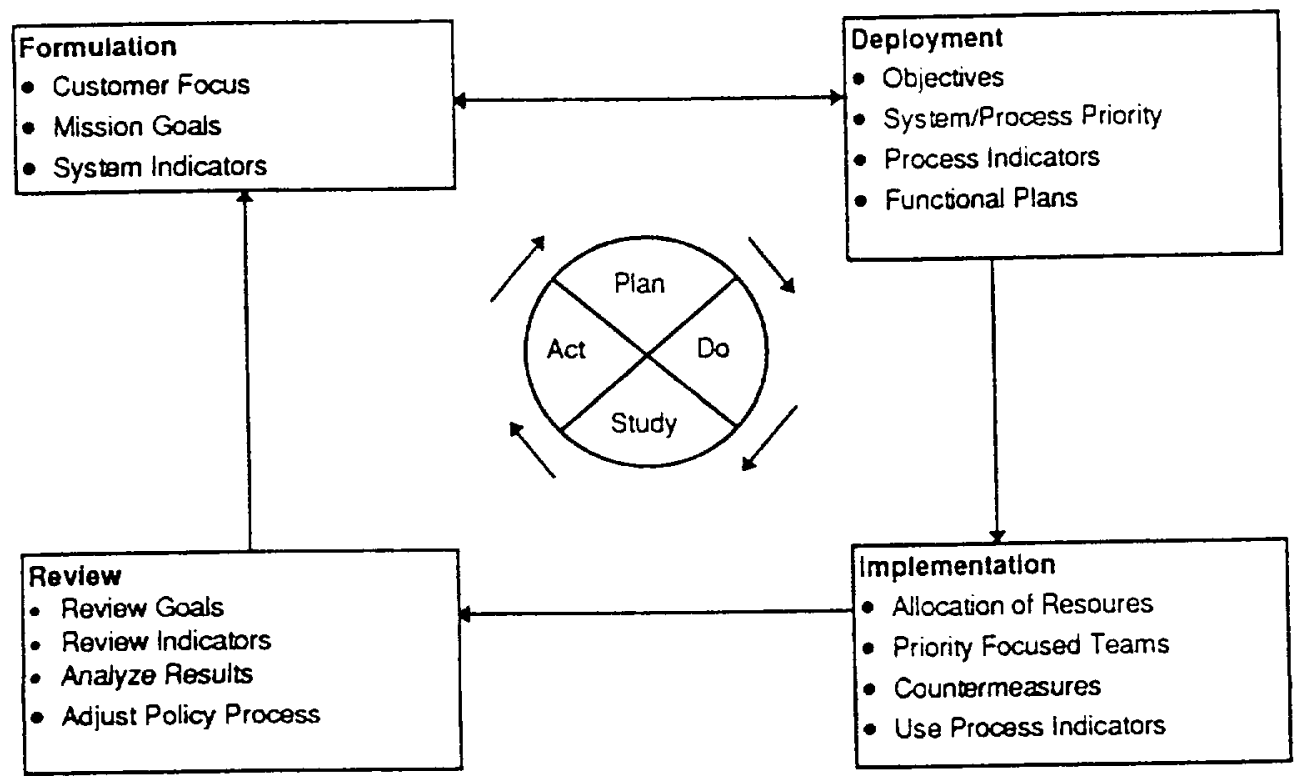

Figure 1: Air Force Quality Focus Method 
the changes are made to the process, and the continuous improvement process goes to the next iteration. In doing so, the process is refined to best meet customer needs [1:77]

This paper will only focus on part of the formulation phase of the Quality Focus process. There are several reasons for doing this. First. is that the entire process is far beyond the scope of this paper. It would be very difficult with a generic vehicle to the determine functional plans, and impossible to implement and review those plans. Second, it is the purpose of this study to demonstrate a method of analyzing ground operations, not in suggesting changes which would be dependent on a vehicle configuration.

\section{The Formulation Phase}

The components of the formulation phase and their definitions are illustrated in Figure 2 . Those items in bold print are the portions of the formulation stage that are relevant to this paper. The others including Planning to Plan, Values Assessment, and Develop Strategic Goals and Objectives must be determined by the organization conducting the process and are again outside the scope of this study.

- Planning To Plan

- Values Assessment

- Analyze Mission

- Envision The Future

- Assess Current Capabilities

- Gap Analysis

- Develop Strategic Goals And Objectives

Steps in Bold Are Covered in The Paper

Figure 2: Steps of The Formulation Stage

The first two steps to be considered are an analysis of the purpose of the process and envisioning how we would like the process to be in the future. To analyze the mission it is necessary to determine what is of value to launch service customers. Based on what the customer perceives as value. we will envision a turnaround process and vehicle design that will meet those needs.

The remaining steps of the formulation phase are to determine current process capabilities, and the gap between those capabilities and our "vision" of the future. To accomplish these steps requires one key assumption. That is the new turnaround process will be a refinement of an existing turnaround process. For our example, the RLV process would be based on the Space Shuttle process. While many would like the RLV process to be entirely new and separate from earlier Shuttle operations, such an approach has many pitfalls. Most RLV configurations will require many of the same processes that the Shuttle currently requires. While we can not afford to repeat the mistakes of the Shuttle process, neither can we afford to ignore the lessons learned. For this study the Shuttle and its turnaround process will be our current capability. and the gap between the Shuttle process and our vision of the RLV future will determine where the current process must be changed.

\section{Analysis Mission}

Simply stated the purpose of the RLV system is to provide launch services to Low Earth Orbit (LEO). This is to be accomplished providing the greatest value to the launch services customer, while providing the vendor of launch services a reasonable profit. One of the keys to customer value is found in turnaround operations.

The mission of turnaround operations is to return the vehicle to flight status after the preceding mission. This includes safeing the vehicle, conducting necessary inspections, replacing components that have failed (or that are estimated to fail during the next mission), and servicing the vehicle for the next mission. How this is accomplished, including the time allotted, is determined based on customer requirements.

But customer requirements have many factors, with varying importance depending on the customer's activities. A presentation by Rhodes [2] of NASA KSC, at the AIAA Space Operations and Support Technical Committee, Low Cost Operations Workshop provides breakdown of these factors. While the original purpose of the presentation was launch system affordability, it closely relates to customer value.

Figure 3 illustrates the breakdown of affordability factors. At the top of the hierarchy is the overall affordability of the launch system. This is in turn broken down into non-recurring and recurring costs. In other terms, these are the cost of system development and system operations respectively.

Non-recurring costs can be broken down into program acquisition cost and technology research and development. Technology research and development costs are the long-lead investments necessary to identify, develop, demonstrate, and mature technologies so that they are ready in time for system development. Program acquisition costs are the costs of system development. This includes the actual cost of design, manufacturing, and their infrastructure; as well as costs related to programmatic and technical risk. The impact of nonrecurring costs on the customer value depends on 


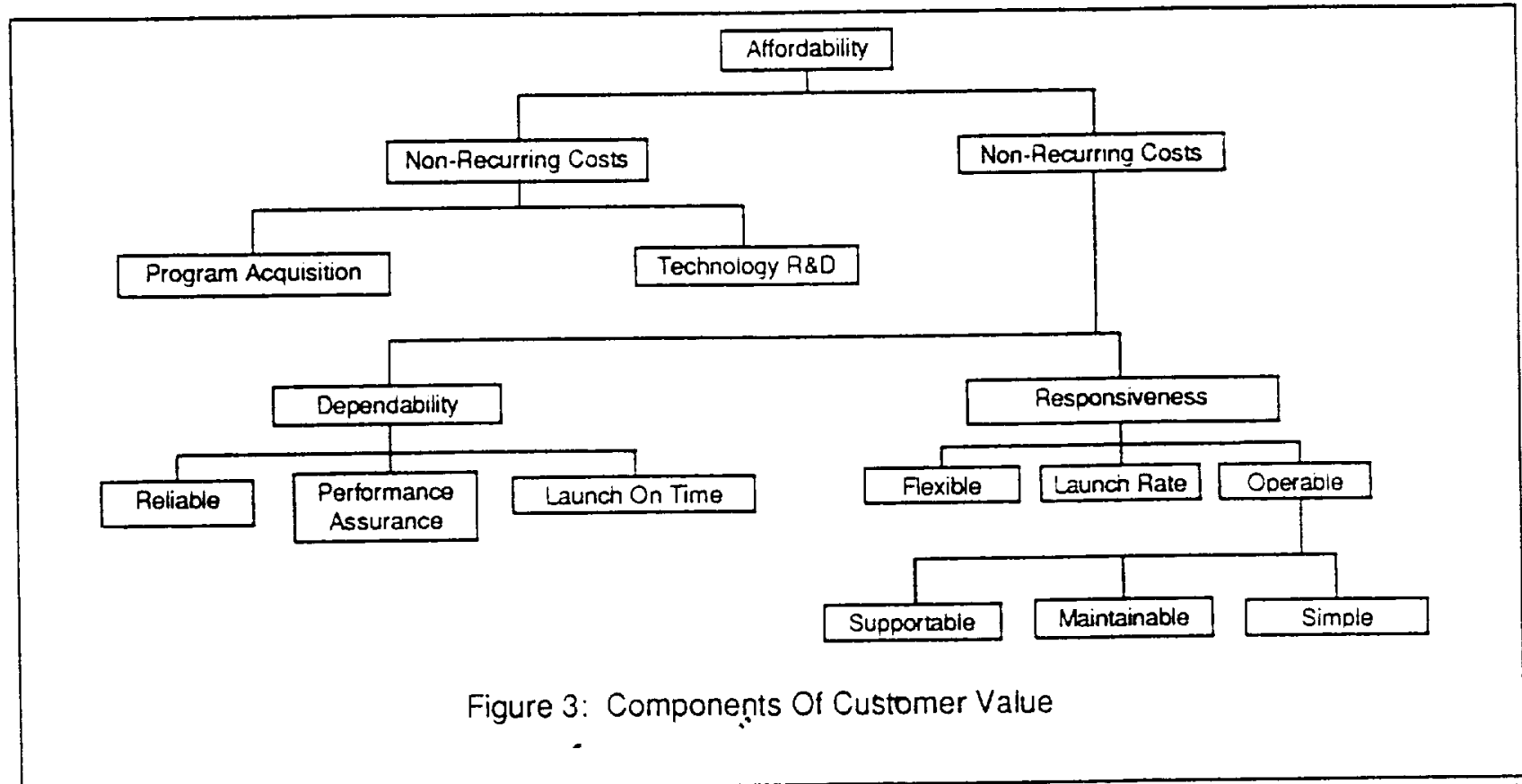

how the system operator decides to amortize their investment. This falls outside the scope of this paper.

Recurring costs-are the main focus because these costs are directly related to turnaround operations. In addition, these costs will make or break the marketability of a reusable launch system. Like non-recurring costs, recurring costs can be broken down into two areas, dependability and responsiveness. These areas, in addition to vehicle performance are the key drivers of customer value.

Dependability is the ability of the system to perform as scheduled. This includes both the timeliness of a mission as well as the success of the mission. It can be broken down into three factors; Reliability, Performance Assurance, and Launch on Time. Reliability is the probability that the system will operate as planned. For the RLV, reliability is measured with three tactors: (1) mission reliability, the probability of flying the mission as planned, (2) vehicle recoverability, the probability that the vehicle will survive a mission, (3) passenger safe return, the probability of recovering the passengers (even if the vehicle is lost). The value of reliability to the customer depends on their needs. For example, if the customer is considering whether to launch on an expendable or reusable system, mission reliability is primary; vehicle recovery is the operator's problem. For a Space Station crew rotation mission, all three reliability parameters are important. In this case, the customer is concerned with all mission phases from launch to the safe return of the station crew and the recovery of experiments being returned from orbit.

Dependability is also a function of performance assurance. This is the vehicle's robustness including operating margins and fault tolerances. Increased performance assurance means that the system has greater flexibility. The value to the customer here is the vehicle's ability to operate in a wide variety of conditions. The more restrictive the performance assurance, the more likely are launch delays.

Finally, dependability is a function of the systems ability to launch on time. This means that the launch system and its various processes are designed to meet the requirements of the mission manifest. Timeliness is based on the launch date set when the customer contracts for services, not when the vehicle is available for flight. The value to the customer is confidence in the launch date.

The second area under recurring costs is responsiveness. It too can be broken down into greater detail. Its components are Flexibility, Launch Rate, and Operability. For the customer flexibility means that the system is capable of changing to meet their needs rather than the other way around. Responsiveness is also a function of launch rate, which in turn is related to flexibility. Responsivness is the capability to have the system available on demand, and to accommodate rapid response requirements.

Finally responsiveness is a function of operability. Operability is the attributes of the launch system that allow it meet mission requirements and manifesting. To the customer, operability is a direct concern, since the impact of operability is manifest in the other factors of dependability and responsiveness. In addition, operability is a major impact operating costs which are transferred to the customer.

Operability breaks down into Maintainability, Supportability, and Simplicity. Maintainability is a design factor that measures the ability of the operator to maintain the system. It measures include vehicle service requirements, access to 
vehicle systems, and the processes necessary maintain the vehicle; with simplicity being the key. Another consideration of operability is supportability. Supportability is what it takes to support system operations. It includes such diverse areas as logistics, personnel, and administration. Again the key is simplicity. The last factor is simplicity of design. The less complex the systems, the less likely there will be failures. Again these are not really value items for the customers to consider, rather they are factors that the system designers and operators must consider to drive theose parameters which are of value to the customer.

In summary, the value of launch services is in the eyes of the customer. Since it would be beyond the scope of this paper to survey customer requirements, the following assumption is made: For the launch services customer, the primary factors in the value of services are cost, reliability, flexibility, and schedule dependability. The customer would expect to pay a reasonable price for the launch services. Which would drive the launch system operator to streamline turnaround operations as much as possible. The customer also values the reliability of the system. Which would drive the turnaround process 10 ensure that required maintenance and servicing is accomplish before flight, but without adding unnecessary inspections which drive costs up. Flexibility is also assumed to be major value point for the launch services customer. It ensures the customer that special or changing mission requirements can be met. Finally, schedule dependability ensures that customer that the contracted services will be there when required.

\section{Future Vision}

The second step of the quality focus method is the future vision, a vision of where we want to be. One source of this vision is the Cooperative Agreement Notice (CAN) for the Reusable Launch Vehicle Demonstrator (X-33). [3] While this document was concerned with a demonstrator of technologies required for a reusable launch vehicle. it also calls out goals for a future RLV.

Table 1 lists the minimum operations requirements for the reusable launch vehicle. Each of these requirements will be an improvement to the existing capabilities of the Shuttle. This includes the automation of pre-flight and flight operations, a seven day maximum turnaround and a 3.5 day maximum emergency turnaround. Under operability there are requirements for schedule dependency and robustness. Finally for reliability it includes probabilities for safe recovery of the vehicle and the crew. ${ }^{1}$

\section{Table 1: X-33 CAN Requirements And Goals For RLV}

- Automated pre-flight and flight Req operations (launch, ascent, on-orbit, reentry and landing

- The flight vehicle shall be capable of safely aborting to the launch site during the ascent phase if required

- Seven day maximum mission duration

Req

- Seven day ground processing time from landing to launch

- 3.5 day ground processing time from ' Randing to launch for reflight under emergency conditions

- The probability of launching within Req TBD (sic) days of scheduled is .95

- Maximize responsiveness to adverse Req weather conditions

- Launch and landing at same location Req (nominal condition)

- The flight vehicle shall be capable of Req unplanned landing at alternative landing sites with minimal support equipment and facilities

- To the extent practical, on-board Req subsystems required for flight vehicle shall be field repairable/replaceable

- Equipment required to repair, process Req and return vehicle to launch site shall be transportable

- .995 Probability of safe recovery of the Req flight vehicle per mission

- .999 Probability of safe recovery of the Req human passengers per mission

The requirements spelled out in the CAN drive the overall goals of a new launch vehicle, but they

\footnotetext{
There is no reliability given for mission reliability. In fact the .995 probability vehicle recovery has proven to be a much more stringent requirement on the system than the .98 mission reliability that has generally been mentioned.
} 
do not give any direction on how those goals will be achieved. It would be up to the system developer to determine guidelines for meeting the overail goals. An example of these guidelines, is illustrated in Table 2. This is a "vision" of an RLV operations concept developed by the Vehicle Engineering Directorate at the Kennedy Space Center. [4]

This list is a "vision" of the attributes that a future launch system would have based on past experience with other launch systems, particularly the Shuttle. It is not a list of requirements, but rather goals to be met in the future. The "vision" calls for a system that is highly automated or autonomous, meaning less of a standing army and Ground Support Equipment (GSE) necessary to process the system. It also calls for a more simplified and robust vehicle that has wider operating margins requiring lewer periodic inspections and vehicle type certification like aircraft, rather than individual flight certification as on the Shuttle. The processing of the system is also more simplified and interfaces -between the ground and payloads are more standardized. Finally, it envisions a system where operations, vehicle systems, and payloads ail have an input into the vehicle design.

In summary, the future vision of a launch system is a goal that we are designing to reach. For this example the assumed vision of lurnaround operations is a relatively simple process that is conducted with a high degree of automation. The process is relatively uncomplicated and strives toward aircraft operations, meaning replenishment of consumables and correction of failures. There is no recertification with attendant testing and inspections. The process is highly reliable and robust, meaning few failures of flight and ground systems during processing. The process meets scheduled launch dates with a high degree of dependability, and is highly flexible, capable of accommodating late changes to payload or schedule.

\section{Assess Current Capability}

The next step is to evaluate our current capabilities, in this case the current status of the Space Shuttle. Because of the many aspects of turnaround processing, a proper assessment would again be far beyond the scope of this paper. As a result we will consider only the value of schedule dependency to the customer in our RLV / Shuttle example.

One of the major criticisms of the Space Shuttle is its launch delays. While the most publicized of the delays are on-pad delays, there are many other delays that account for a much greater schedule slips. In fact changes in the launch date are based on three factors: First, the variability in mission planning times. Second, variability in vehicle turnaround processing times. Finally, the impact of

\section{Table 2: RLV Operations Concept "VISION"}

- Provide a simplified, very-highly automated vehicle enabling minimum periodic and repetitive maintenance.

- Strive to isolate vehicle ground processing from dependence on lacilities and GSE. Routine turnaround should replenish consumables only.

- Promote vehicle health monitoring management systems and self-test at a level which supplies only O\&M related information that requires corrective action prior to next flight.

- Eliminate "flight readiness-style" vehicle .. recertification for every flight. Provide aircraft-style vehicle-type certificate.

- Design in performance margins and flight hardware allowances to eliminate processing impacts (i.e. strive to eliminate unscheduled work.)

- Reduce operations and hardware complexity for maximum utilization of resources and eliminate opportunity for human-induced system failures.

- Employ near autonomous ground management planning at top levels. Focus on automatic interactive scheduling of flight vehicle, ground support facilities, and support logistics.

- Adapt minimum standardized payload interfaces to assure maximum flexibility and affordability.

on-pad delays due to weather, and ground or flight system failures.

Delays due to mission planning occur from the time the customer and the operator agree on a contract for launch services until all planning and preparation for the mission are complete. For the Shuttle, delays are due to changes in the manifest: delays in planning mission timelines, crew training, and unavailability of facilities or equipment. Many of these problems are due to the need to assign a specific vehicle to the mission earlier in the process. This is due to differences in vehicle flight attributes and can make a mission dependent on all of the prior missions using that vehicle. Unfortunately there is no data kept on this type of delay. As a result it is impossible to assess the problem or to develop an analysis of the gap between the current process and 
our envisioned process. Fortunately the general RLV concept calling for "mass produced", identical vehicles with standard payload interfaces may take care of this type of delay. In addition, automated mission planning may also make the planning process more adaptable to changes.

Ground processing delays are the delays that occur because of vehicle and ground systems problems from the time the vehicle lands from the previous mission to the time the next countdown starts. These delays can be attributed to either vehicle system failures or failures in the turnaround process. Since we would like to have the greatest impact for the design dollar, our assessment must identify which subsystems and processes are giving us the greatest problems.

Vehicle systems failures impact two customer concerns, reliability of the system and schedule dependability. To properly evaluate subsystem and component reliability a large data base of component failure data is required. Unfortunately, the Shuttle data collection system is not designed to track component failure rates. As an indicator of relative subsystem failure rates we will use the historical vehicle flight failure data.

Figure $4[5: 78]$ shows the distribution of failures attributed to each subsystem for vehicle failures (excluding failures attributed to payloads or upper stages). The bars labeled for all failures consider all launches by any vehicle ever used for space launch operations, with data going back to 1954 . For ballistic missiles later used for space launches, it includes the ballistic launches. The data is also cut for launches after 1970. These are assumed to be a better indicator of current capability, since they do not include early launches by less sophisticated vehicles.

Note that Figure 4 is for loss of mission. A loss of mission failure for the RLV is defined as a failure where the vehicle could not complete its mission. This type of failure may or may not result in the loss of the vehicle. This results in an obvious conflict with expendable vehicles which are never recovered, and which make up the vast majority of historical data. Because there is so little historical data on reusable vehicles, it is necessary to use the expendable data to get a better estimate of current launch vehicle reliability. Since expendable and reusable launch vehicle have many similar subsystems, though operating for different periods of time, it seems reasonable to use the data for a first cut at reliabilities.

In examining the figure, note that the propulsion system has always been a major contributor to loss of mission. For this analysis, the propulsion system is considered to be anything up stream of the turbopumps, including fuel storage and leed systems, vent/purge systems, and the pressurization system. While it appears that this problem is worse in the 1970 and later data, this can be deceiving. What this data shows is the percentage of all tailures by subsystem. The reliability of the propulsion system is improving, but not to the extent of other subsystems. As a result, the proportion of failures contributed by the propulsion system is considerably greater.

Based on the historical data a success ratio, total success/total launches, can be derived. The values for current launch vehicles (expendable and reusable) flown since 1970 are listed in Table 3. This data will be considered as the current level for subsystem reliability. In the next section we will compare it to the what is required in the RLV vision.

As noted earlier, turnaround process reliability also impacts customer value. A study by flemming [6] of Lockheed Martin, looked at the impact of

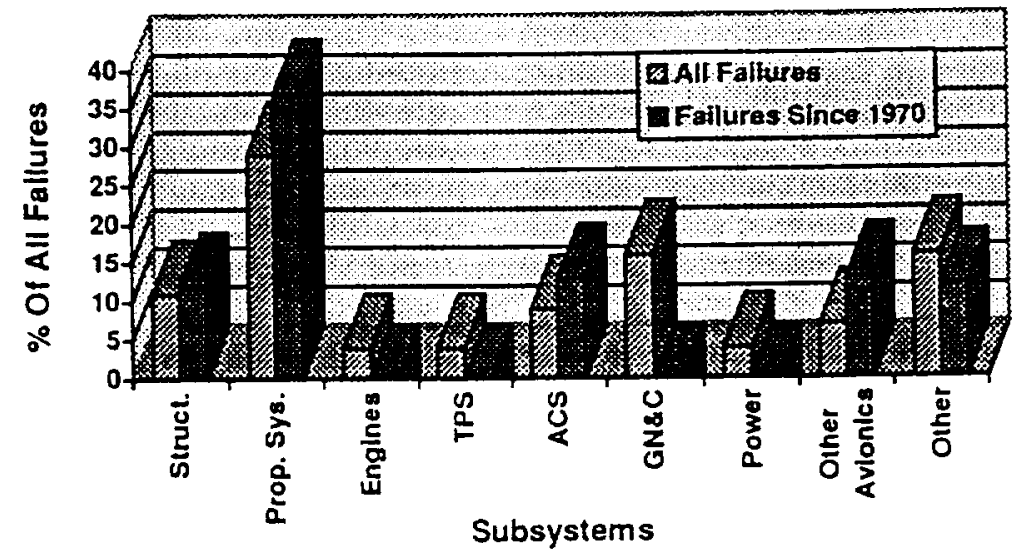

Figure 4: Breakdown of Vehicle Flight Failures By Subsystem 
process reliability on turnaround processing flow times. The reliability of a process for this study was the percent of the time when no problems were encounter during that specific process. The study looked at the seven processes that are part of the

\begin{tabular}{|lc|}
\hline \multicolumn{2}{|c|}{ Table 3: Estimated SubSytem Reliability } \\
Sibstem & Success Ratio \\
Siructures & .9979 \\
Propulsion Systems & .9764 \\
Engines & .9914 \\
Thermal Protection System & .9979 \\
Attitude Control System & .9979 \\
Avionics & .9935 \\
GN\&C & .9999 \\
Power & .9936 \\
Other Avionics & .9999 \\
Human & .9936 \\
Other Unknown & .9936 \\
\hline
\end{tabular}

overall Shuttle turnaround process. These include mechanical, electrical, propulsion, thermal protection, avionics, and landing gear system checkouts; and propellant loading.

The study used Problem Report (PR) data from the Shuttle turnaround process. This data consisted of the number of process runs that contained failures, the total number of process runs, and measures of Mean Time To Repair (MTTR). Actually the evaluation used three measures of MTTR. The first (MTTR 1) was hands-on repair time which starts when troubleshooting is complete and continues until the repairs are complete except for testing and closeout. The second measure (MTTR 2) is active repair time and includes all of the first measure plus troubleshooting, test time, and closeout. The final measure of MTTR (MTTR 3 ) is the overall repair time which includes active repair time plus any administrative time. With the MTTR calculated, the dollar cost of process unreliability can be calculated by using a average hourly compensation rate.

A summary of the data for the Shuttle turnaround process (current baseline) is shown in Table 4. The data includes the process success ratio for each of the listed areas. The data will be used to determine the process reliability "gap" between the current turnaround process and the reliability required to fit the time constraints of our RLV vision.

\begin{tabular}{|lc|}
\hline Table 4: Current Shuttle Process Reliability \\
& $\begin{array}{c}\text { Success } \\
\text { Process }\end{array}$ \\
Ratio \\
Propulsion Systems Checkout & .80 \\
Mechanical Systems Checkout & .64 \\
Electrical Systems Checkout & .72 \\
Avionics Systems Checkout & .63 \\
Thermal Protection System Checkout & .60 \\
Landing Gear Checkout & .25 \\
Propellant Loading & .20 \\
\hline
\end{tabular}

The final type of delay to be evaluated is the onpad delay. While these delays generally result in the least impact to the scheduled launch date, their visibility to the public and the media give them much more weight. The impact of these delays may increase with the start of space station missions. These missions require much shorter launch windows due to the need to reduce orbital phasing times to a minimum. The phasing time needs to be minimized since longer times in orbit will drive the

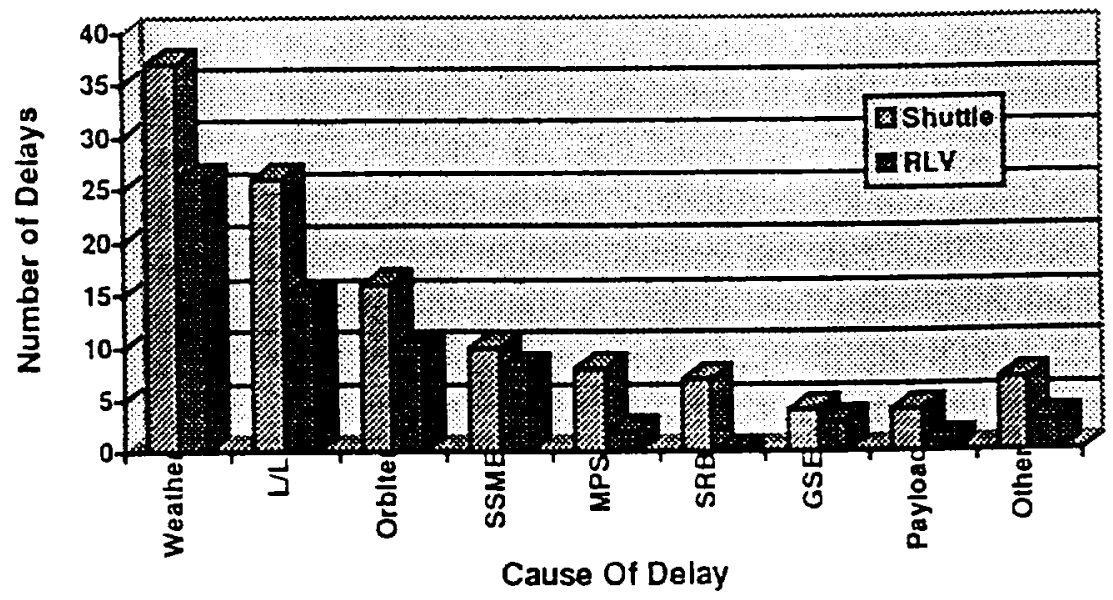

Figure 5: Comparison Of Shuttle And RLV Launch Delays 
design of the subsystems and will usually result in unacceptable weight increases. It is generally accepted that a launch window of five minutes will be allowed.

The launch delay data illustrated in Figure 5 is for the Space Shuttle, and was collected by Weldon [7] of NASA MSFC. The figure shows the number of delays attributed to weather and vehicle systems. The data includes both delays that extend beyond the launch day, and delays that result in a launch later in the window, but in the same day. As the figure shows, weather at the launch site or at the abort sites (coded $L L$ ) cause the most delays.

But this data can be misleading. Figure 6 , based on Lockheed Martin Operations data [8], compares the number of delays to the cumulative length of the delays. When the data is based on the number of delays, regardless of length, weather is the largest cause of delays. When the data is based on the cumulative number of delay days, then the liquid propulsion system is biggest contributor to delays. To the customer the latter is the true driver. It is many times important to look at data from several different views to determine the true problem.

Note that this data is only down to the subsystem level, which is sufficient for this example. In actuality the data must be down to the component level to be useful for continuous improvement efforts. It is essential that future launch systems develop a data collection and analysis system prior to the vehicle going operational. Lack of such a data collection system for the Shuttle is a major shortcoming in attempting to apply past experience to future programs.

\section{Gap Analysis}

The final step that we will take in our analysis of turnaround processing will be that of gap analysis. This determines the gap between what our current capability and the capability of our "vision" of the future. The product of this analysis is a list of problem areas that must be solved to maximize customer value. Prioritizing this list by customer value will result in maximizing customer satisfaction with limited funds. As noted in the previous section, schedule dependability is based on vehicle and process reliability, and on-pad launch delays. We will first consider vehicle reliability.

To determine the gap between our current and required reliability it is first necessary to determine a quantifiable vision. The $X-33$ Cooperative Agreement Notice (CAN) provides two goals, a .995 probability of vehicle recovery and a .999 probability of safe passenger return. Which of these two goals drive the system design depends on the venicle escape system and other factors. To simplify things we will go with the vehicle recovery goal.

Subsystem goals can be achieved by allocating "allowed" failures between the subsystem based on the historical distribution of failures. In this case a reliability of .995 means that nominally there would be five failures per thousand flights. If in the past, propulsion system failures (not including engine failures) accounted for 40 percent of the failures then 40 percent of the five failures would be allocated to propulsion systems. The result would be a goal of two failures per thousand flights or .998 reliability. The allocations can be made down to

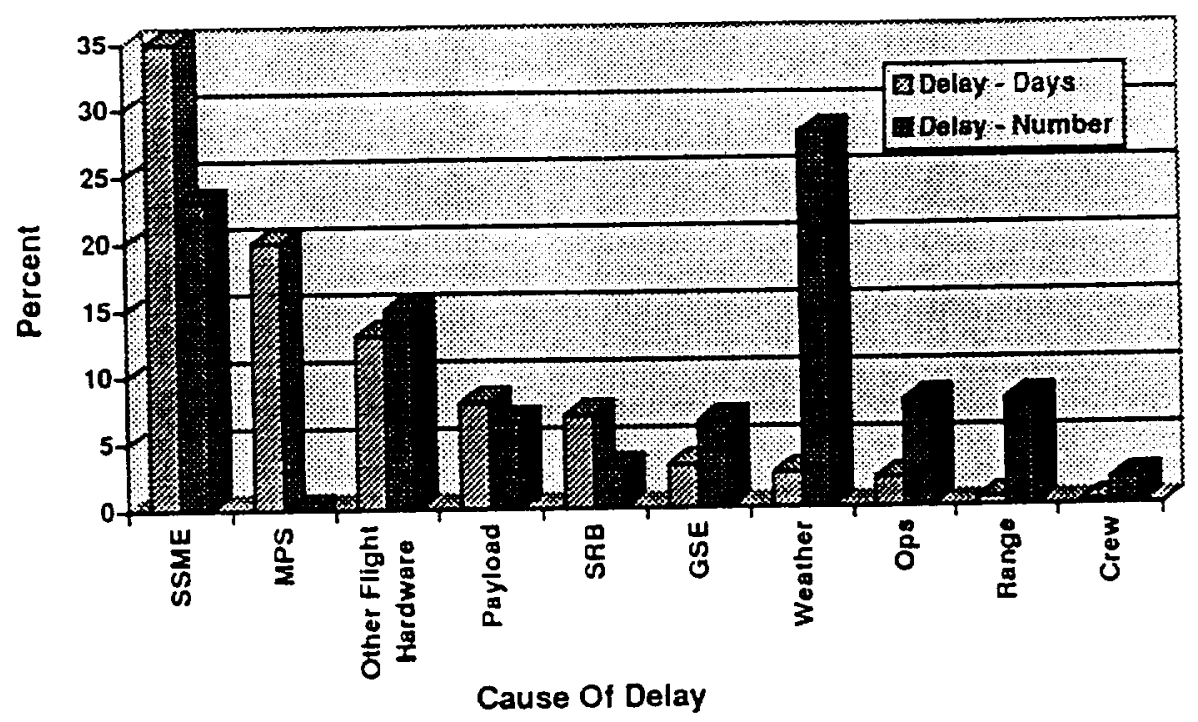

Figure 6: Number Of Delays Vs. Days Delay 
whatever level that failure data allows.

Once the reliability goals are determined it is necessary to evaluate what will be necessary to meet those goals. In the case of reliability goals, reliability growth ${ }^{2}$ of existing systems must be projected to determine if the reliability goals can be met with reliability growth alone. If it can not be accomplished then it is necessary to look to new designs and processes.

There are many methods which can be used to assess reliability growth. The results of two such methods are illustrated on Table 5 . The columns title "Trend Estimate" and "Trend Forecast" are based on a regression equation that is an estimate of the instantaneous success ratio (total success over total flights). The "Trend Estimate" is an estimate of the current success ratio calculated from the equation for the present number of flights. The "Trend Forecast" is an estimate of subsystem reliability for 200 flights into the future. The value of 200 was used because the average U.S. flight rate (all vehicles) is about 20 flights per year multiplied

Table 5: Reliability Allocations And Proiections

\begin{tabular}{|l|c|c|c|c|}
\hline \multicolumn{1}{|c|}{ Subsystem } & -Allocation & $\begin{array}{c}\text { Trend } \\
\text { Estimate }\end{array}$ & $\begin{array}{c}\text { Trend } \\
\text { Forecast }\end{array}$ & $\begin{array}{c}\text { Rockwell } \\
\text { Estimate }\end{array}$ \\
\hline Structures & .9994 & .9854 & .9870 & .9996 \\
\hline Prop. Systems & .9982 & .9311 & .9411 & .9984 \\
\hline Engines & .9994 & .9943 & .9943 & .9943 \\
\hline TPS & .9999 & & & .9999 \\
\hline Avionics & .9993 & .9666 & .9726 & .9998 \\
\hline
\end{tabular}

- Indicates That This Was Nol Considered

Data Base On Launch Data Since 1970

by the ten years (at the time of the study) until the RLV is operational. These estimates were derived from a trend model fitted to data in the United States Launch Experience Data Base maintained by MSFC, Program Development, Operations Analysis Branch. [9]

The last column on Figure 7, entitled "Rockwell Estimate" is based on projects using the Rockwell MATrix model. The model is based on Shuttle data, and uses a proprietary model to forecast reliability based on vehicle characteristics and attributes. The results show a much more optimistic view of meeting our reliability goals because it assumes greater reliability improvements than simply reliability growth from flying the same hardware more often. The point is that in analyzing the gap you must be clear on the quality of the data, the accuracy of the

\footnotetext{
${ }^{2}$ Reliability growth is the increase reliability of a product as it matures. High failure rates in the early in the product give way to lower rates as the design matures. Thus, more testing and operational data should show fewer failures causing the reliability 10 grow.
}

modeling techniques, and the assumptions necessary to gain the results.

For the case illustrated here, the reliability estimates in the column titled "Trend Estimate" may be considered lower bounds on subsystem reliability. Future launch vehicle subsystem reliability should be at least as good as these estimates. The estimates in the column "Trend Forecast" suggest that subsystem reliability for launch vehicles has, in general, been improving since 1970 and may be expected to improve. The Rockwell predictions, in turn, may be considered achievable upper bounds on subsystem reliability. The allocated reliability for all but one subsystem (engines) are less that the Rockwell estimates. This would indicate that improvements in reliability, beyond that of reliability growth, are required to meet the goals. In any case development goals and strategies would be based on the gap analysis and the confidence in the results.

The gap analysis of ground process reliability requires a comparison between the current Shuttle turnaround process and the turnaround process vision. This includes: (1) Develop a "vision" of lurnaround processing. (2) Determine the time required to accomplish each task based on previous experience. Allocate the turnaround processing goal to process steps. (4) Determining the variability (reliability) of each task.

Prioritize process steps requiring change by cost to benefits ratio.

The first three tasks of the process analyses require the development of a turnaround processing timeline. Figure 7 illustrates an example of a turnaround processing flow $[5: 111]^{3}$. The example is derived from a Shuttle flow, essentially without modification. It is based on a generic RLV which contains subsystems common to most current RLV designs. Further, it was designed to match a 96 hour turnaround goal and individual task times are allocations. Note, this in no way indicates that this process flow is feasible, because it simply proportions time.

The next step would to be to validate the process by determining the feasibility of the process times, and by eliminating those tasks that are unnecessary for the specific RLV design. This step can be long and involved. It would require breaking the each task down to the lowest level possible and

\footnotetext{
${ }^{3}$ This is just and example, and does not fit the RLV need for a quick turnaround
} 


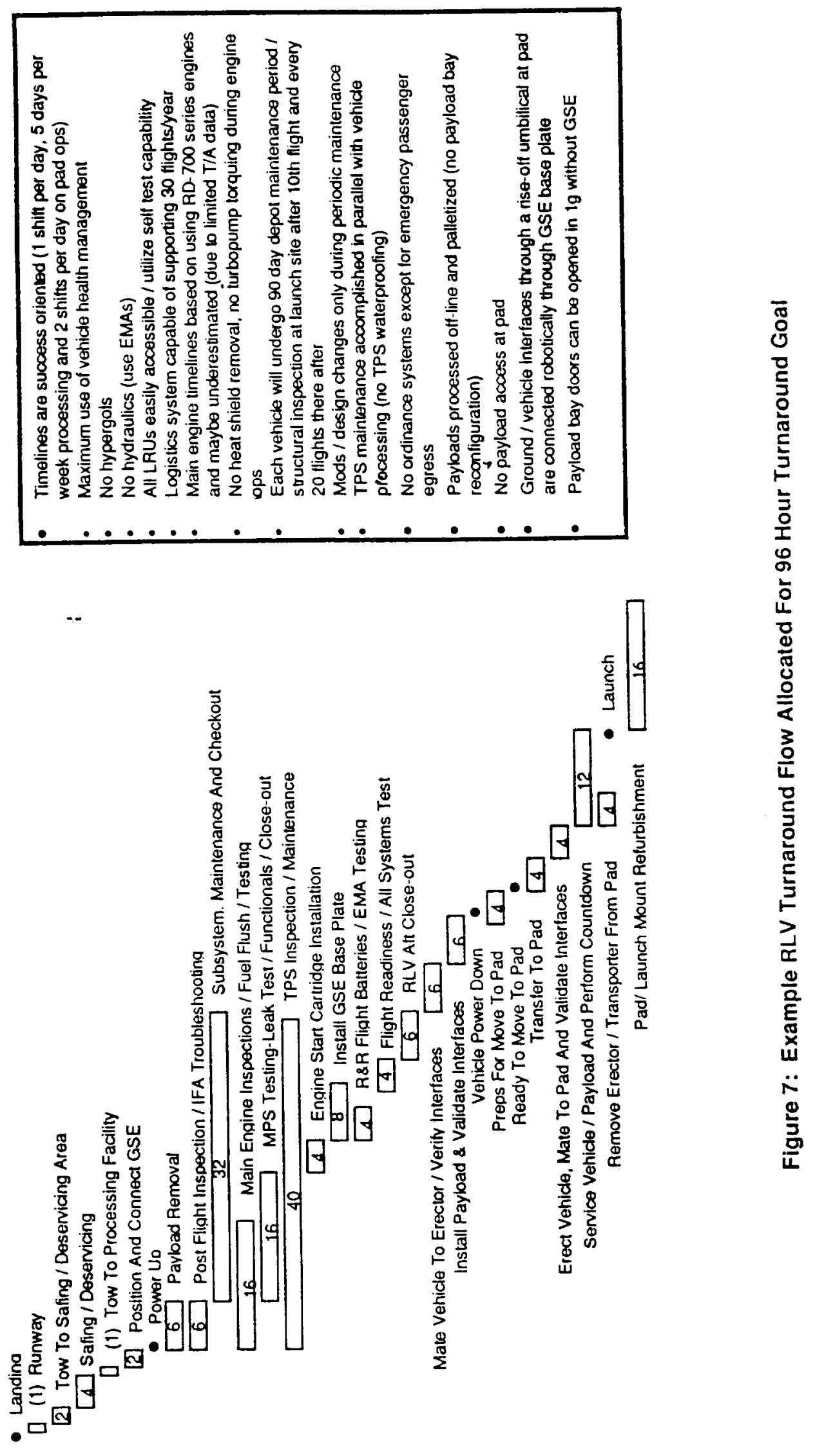


determine whether each subtask is required, then summing the times back to the task level. To do this requires an adequate data base of historical tasks and timelines. Unifortunately, the availability of such data is limited. since operational data is not readily available at the component level.

As a final comment the example obviously does not fit the vision that we set forward earlier. But it is indicative of the long way that we will have to go from the first generation reusable vehicle (Shuttle) to the next generation (RLV).

Assuming that the example turnaround processing flow has been validated, it is now necessary to look at the reliability of the process. Table 4 presented the reliability for various lasks within the turnaround process. Based on this data, a nomograph of the relationship of reliability versus processing time and cost can be constructed. The nomograph is constructed by deriving the failure rate from the reliability, measures of repair time, and the cost of labor. An example of the this type of nomograph is displayed in Figure 8.

The nomograph can be used to determine what needs to be done to a process step. First, convert

Shuttle operational history of delays to projections for an RLV. The RLV delays include all Shuttle delays for weather and all delays for system problems where the RLV has equivalent systems. For example, Shuttle Solid Rocket Booster problems would not be included, but most avionics problems would be included.

The data in Table 7 cuts the data in several ways. The two major columns are for probability of launch anywhere in a launch window and for launch within the first five minutes of a launch window opening. The latter would be for missions to the Space Station that have only a five minute launch window. The rows cut the data into the probability of launch on the day scheduled at the Flight Readiness Review (FRR); the probability of launch on the first attempt, regardless of schedule; and the probability of launch on any attempt. Again this is for a generic RLV and actual designs will refine the estimates.

\section{Summary}

This paper has advocated and illustrated the use of continuous improvement techniques in the Taking the operations data from an existing vehicle baseline and the requirements for a new vehicle as a goal, a systematic approach to vehicle and operation design can be found through continuous improvement techniques.

The United States Air Force "Quality Focus" method was used as a methodology for continuous improvement. The methodology is based on the Shewhart Cycle which uses a four step process for improvement; plan, do, study and act. Or formulate, deployment, implement,

the allocated task time to corrective maintenance cost using average hourly labor costs. Then choose the appropriate MTTR curve and determine what reliability is required to meet the allocations. If that level of reliability does not seem reasonable then basic changes must be made to the process or the hardware.

The final example of gap analysis is for on-pad launch delays. This is handled much like turnaround processing reliability. The current delay data was presented in Figures 5 and 6 . Based on the design of the vehicle and ground systems some of those delays would not be applicable to the RLV, and would be excluded from the data. The remaining delay data can be statistically analyzed to determine the likelihood of launch or the confidence of having a launch over a given period.

Table 6 illustrates some of the data that can be derived from delay data. This table compares the and review for Quality Focus.

In this paper we concentrated on the formulation stage. During this stage the organization must clearly identify the purpose of the process by identifying the organization's mission, customers, and the customer's needs and requirements. Four steps of the formulation process are the key to the design: (1) Analyze the mission of the proposed system; (2) Determine the "vision" of the proposed system by determining the system goals and requirements; (3) Analyze current capabilities; (4) Determine the gap between the current capabilities and the vision. After determining the gaps to be filled, a strategy is developed for the design and development process of the launch system.

Using the Total Quality Management techniques in the development of launch system provides a 
Table 6: Summary Of Launch Dependability

\begin{tabular}{|l|c|c|c|c|}
\hline & \multicolumn{2}{|c|}{$\begin{array}{c}\text { Probability Of Launch Within } \\
\text { Window }\end{array}$} & \multicolumn{2}{c|}{$\begin{array}{c}\text { Probability Of Launch Within } \\
\text { Five Minute Window }\end{array}$} \\
\hline & Shuttle & RLV & Shuttle & RLV \\
\hline First Scheduled Date & .37 & .59 & .22 & .40 \\
\hline First Attempt & .56 & .74 & .27 & .51 \\
\hline Any Attempt & .57 & .72 & .28 & .5 \\
\hline
\end{tabular}

logical way to develop a launch system. For launch operations it means working to streamline operations to those tasks that provide value to the customer. In addition, concentrating on customer value should also drive a more operations oriented design.

The use of these techniques in the development of a new system does change the way we tend to operate. First and foremost of these is developing design discipline. In most projects there is a urge to dive into the design of a system before really defining the goal of the project or final product. Using a more systematic method has great benefits but requires more discipline. The second change is to place more emphasis on the collection of operating data for a system. We need to determine the essential launch system data, including ground processing data, and to ensure it is collected. Unless this data is collected all future designs will be based on assumptioñs of what happened in the past rather than fact.

\section{Acknowledgments}

I would like to thank the members of the "operations group" who have worked tirelessly to make operations part of the design process. I would especially like to thank: Bruce Flemming and Steve Black of Lockheed Martin, Russell E. Rhodes, Edgar Zapota, and Craig McCreary from NASA Kennedy Space Center; R. J. Rector From NASA Johnson Space Center; W. Douglas Morris from NASA Langley Research Center; Rick Christenson, Richard $L$. McKemie, and Danny M. Weldon of NASA Marshall Space Flight Center.

\section{Bibliography}

1. "Quality Air Force", The Quality Approach", as reprinted in Air War College LSN 13, July 1994. pp 70-79, 233.

2. Rhodes, Russell E. and Edgar Zapota, "Space Program Operation Issues". Presented AlAA Space Operations and Support Technical Committee, Low Cost Operations Workshop, May 3-4, 1995 in Washington, DC.
3. "A Cooperative Agreement Nolice, Reusable Launch Vehicle (RLV), Advanced Technology Demonstrator, X-33), National Aeronautics and Space Administration, George C. Marshall Space Flight Center, January 12, 1995.

4. Rhodes, Russell E. "The RLV Operations Concept "VISION", Vehicle Engineering, Kennedy Space Center, November 1994.

5. Brown, Richard W., "Operations Analysis Of The Reusable Launch Vehicle", Program Development, Marshal Space Flight Center, October 31, 1994.

6. Flemming, Bruce A., "RLV Operability Study, Attachment 4 - RLV Operations Assessment", September 1994.

7. Weldon, Danny M., "Operations Analysis Of The Reusable Launch Vehicle - Dependability Study", Program Development, Marshal Space Flight Center, AL, October 31, 1994.

8. Scott, L. P., "Space Shuttle Processing Overview: Space Shuttle Cost Analysis and Launch Delays", Lockheed Space Operations Company, Titusville, FL.

9. Brown. R. W., "United States Launch Experience Data Base", Program Development, Marshal Space Flight Center, AL October 31, 1994.

10. Weber, Theodore F. Jr., "Reusable Launch Vehicle Reliability, Maintainability, and Operability Assessment", NASA Contract NAS8-39210, Rockwell Space Systems Division, Downey, CA. 